\title{
Beneficial effects of coffee in non-alcoholic fatty liver disease: a narrative review
}

\author{
Alessio Calabrò', Anna Caterina Procopio², Francesco Primerano³, Tiziana Larussa², Francesco Luzza², \\ Laura Di Renzo ${ }^{4}$, Antonino De Lorenzo ${ }^{4}$, Paola Gualtieri ${ }^{4}$, Ludovico Abenavoli ${ }^{2}$ \\ 'Indipendent Nutritionist, Viale dei Bizantini 25, Catanzaro 88100, Italy. \\ 2Department of Health Sciences, University "Magna Graecia" of Catanzaro, Viale Europa, Catanzaro 88100, Italy. \\ ${ }^{3}$ Indipendent Biomedical Engineer, Viale degli Aurunci 9, 88060 Montepaone, Catanzaro 88100, Italy. \\ ${ }^{4}$ Department of Biomedicine and Prevention, University of Rome "Tor Vergata", Rome 00133, Italy.
}

Correspondence to: Prof. Ludovico Abenavoli, Department of Health Sciences, University "Magna Graecia" of Catanzaro, Viale Europa, Catanzaro 88100, Italy. E-mail: I.abenavoli@unicz.it

How to cite this article: Calabrò A, Procopio AC, Primerano F, Larussa T, Luzza F, Di Renzo L, De Lorenzo A, Gualtieri P, Abenavoli L. Beneficial effects of coffee in non-alcoholic fatty liver disease: a narrative review. Hepatoma Res 2020;6:69. http://dx.doi.org/10.20517/2394-5079.2020.63

Received: 25 Jun 2020 First Decision: 18 Aug 2020 Revised: 3 Sep 2020 Accepted: 8 Sep 2020 Published: 12 Oct 2020

Academic Editor: Guang-Wen Cao Copy Editor: Cai-Hong Wang Production Editor: Jing Yu

\begin{abstract}
Non-alcoholic fatty liver disease (NAFLD) is one of the most common liver diseases and is related to unhealthy lifestyle habits, characterized by a diet rich in sugars and fats leading to excessive calorie intake, and lack of exercise. In recent years, there is a growing incidence of this pathology, raising the attention of hepatologists, endocrinologists, diabetologists, and nutritionists. In this context, the alimentary regimen adopted by patients with NAFLD has become an increasingly scrutinised parameter. Diet is now considered a crucial factor in the treatment of NAFLD since it has been observed that some functional foods play a beneficial role. These include coffeewhose health effects have already been amply demonstrated. Here we describe the beneficial effects of coffee consumption reported in the NAFLD literature.
\end{abstract}

Keywords: Caffeine, steatosis, functional food, liver disease, antioxidant, chlorogenic-acid

\section{INTRODUCTION}

Non-alcoholic fatty liver disease (NAFLD) is a common liver pathology characterized by fat accumulation in the liver, following a sequence of steatosis, possible evolution in fibrosis, Non-alcoholic steatohepatitis

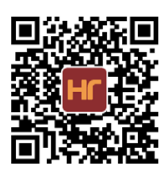



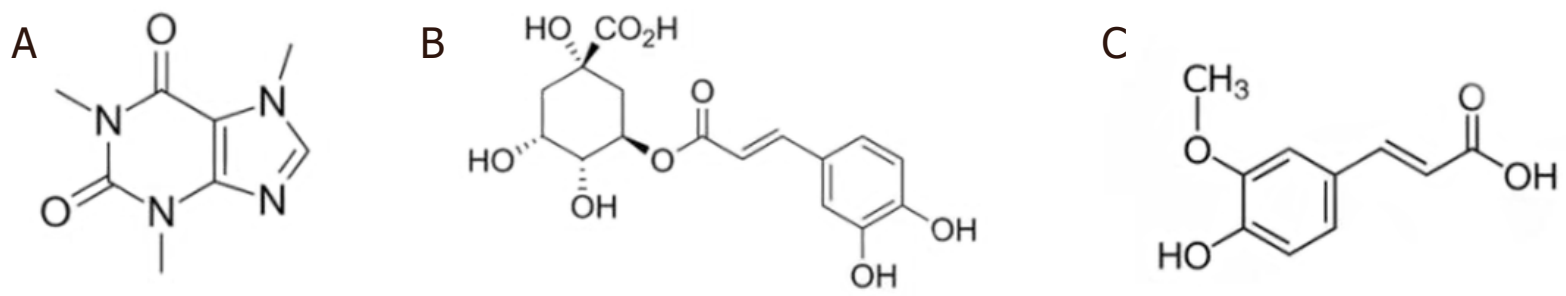

Figure 1. 2D chemical structures of caffeine (A), chlorogenic acid (B), ferulic acid (C)

(NASH), and finally in cirrhosis. Today liver diseases and in particular NAFLD, affects about $25 \%$ of the population worldwide, representing the main cause of chronic liver disease in industrialized countries ${ }^{[1-4]}$.

Lifestyle modifications such as maintaining a healthy diet and regular physical activityare key in reducing the onset of NAFLD ${ }^{[5-9]}$. In particular, it is most important to remove all dietary compounds that can promote NAFLD, for example fructose, saturated fatty acids, carbohydrates with a high glycemic index, and foods with a high sodium content ${ }^{[2,3]}$. Promotion of a balanced diet and loss of excess weight are also important in the context of this clinical condition. The reduction of at least $5 \%$ body weight is effective in reducing hepatic fat accumulation ${ }^{[10,11]}$.

In recent years, the Mediterranean diet has also been accredited as a therapeutic standard in the treatment of NAFLD ${ }^{[12-17]}$. Different studies have showed how functional foods can positively influence our health ${ }^{[5,18-22]}$.

Among the functional foods, we find coffee the most promising; a drink appreciated and consumed all over the world ${ }^{[23]}$. Different beneficial effects have been related to moderate and regular consumption of coffee. In particular, the intake of this drink has proven effective in reducing the risk of type IIdiabetes mellitus, gastrointestinal disorders, Parkinson disease, cardiovascular problems, and gallbladder stones ${ }^{[24-28]}$.

The present review aims to describe the beneficial effects of coffee consumption in patients with NAFLD.

\section{CHEMICAL COMPONENTS OF COFFEE}

Coffee, one of the most consumed beverages in the world, is composed of a large number of substances and polyphenols that contribute to making coffee a real functional food thanks to their beneficial activities. Among the main polyphenols in coffee, chlorogenic acid and ferulic acid [Figure 1] have shown promising antioxidative properties.

The most representative and known compound of coffee is undoubtedly caffeine [Figure 1], an alkaloid naturally present in leaves, seeds, and fruits of coffee, tea, cocoa, cola, and guarana plants. Caffeineis absorbed in the stomach and first portion of the intestine within 10 min after ingestion, reaching a maximum concentration in the bloodstream after 45-60 min. Once absorbed by the body, caffeine is metabolized in the liver where it is converted into three dimethylxanthines: paraxanthine, theobromine, theophylline which contribute to enhancing its effects ${ }^{[2]}$.

In recent years, natural compounds have been the subject of several studies in order to identify their beneficial activities, and in this regard promising antifibrotic effects have been attributed to caffeine [Figure 2].

In particular, caffeine showed promising antifibrotic effect resulting from a series of biochemical processes initiated by liver cell stimulation causing induction of intracellular F-actin and cAMP expression, inhibition 


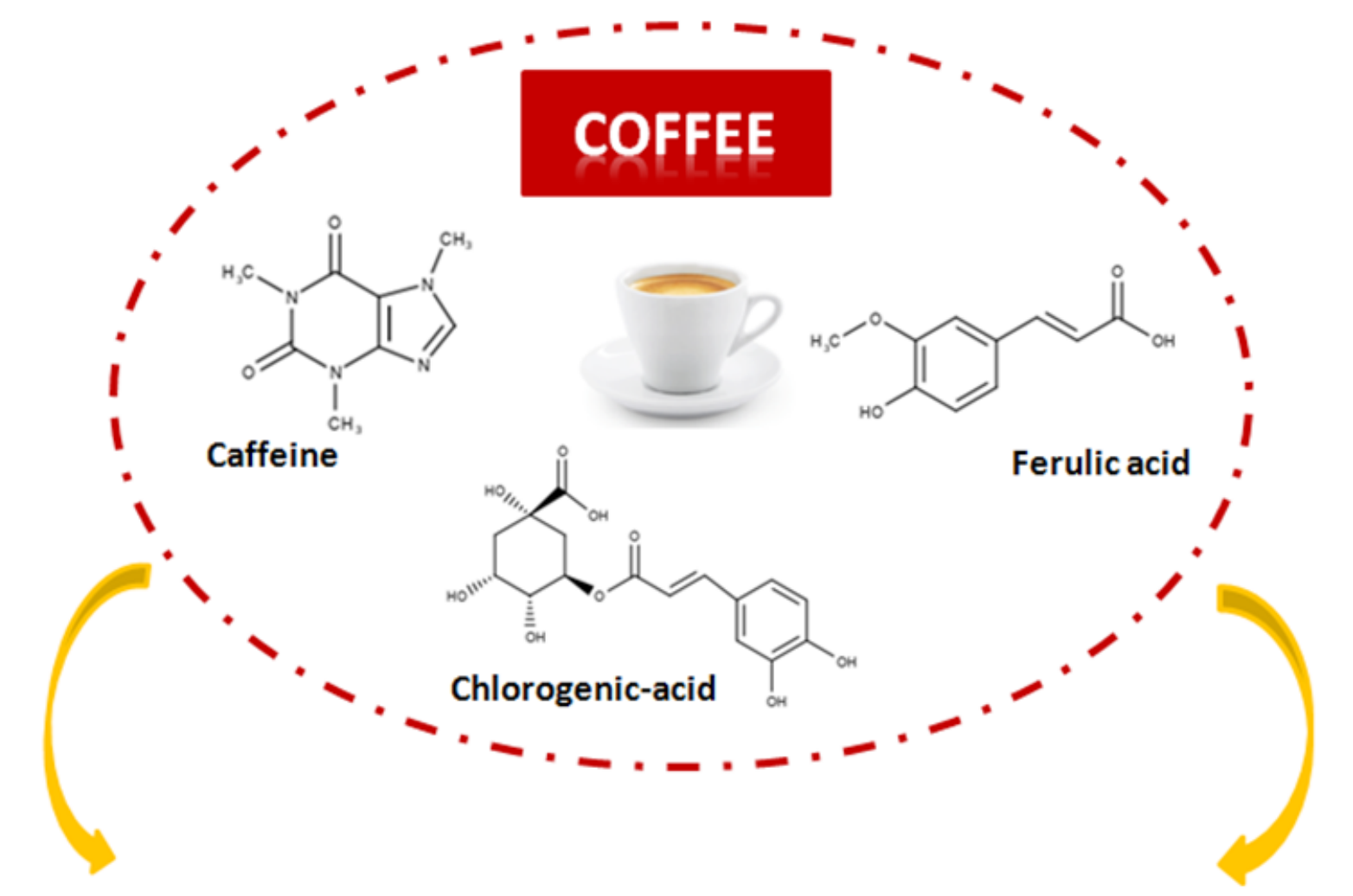

\section{$>\uparrow$ ßeta-oxidation $>\downarrow$ Lipid accumulation $>\downarrow$ oxidative stress}

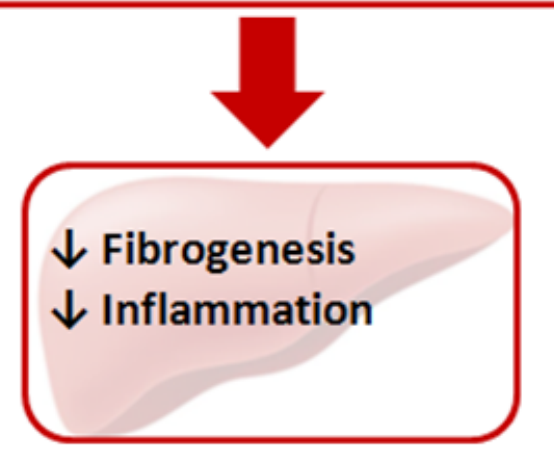

Figure 2. Beneficial effects of coffee on the liver

of focal adhesion kinase, inhibition of $\alpha$-smooth muscle actin ( $\alpha$-sma), and up-regulation of the PPAR- $\alpha$ receptor (Peroxisome proliferator-activated receptor alpha) with action on fat deposits, as shown in Figure $2^{[30,31]}$. Quan et al. ${ }^{[32]}$ showed that caffeine is able to reduce the gene expression of the transcription factors Sterol regulatory element-binding protein 1c and 2 (SREBP1c and SREBP2) in HepG2 cells which are involved in the synthesis of triglycerides and cholesterol in the liver. This down-regulation represents a particularly promising finding as it can facilitate the reduction ofhepatic lipid accumulation typically associated with NAFLD. In addition, caffeine also causes the reduction of 3-hydroxy 3-methylglutaryl CoA reductase and low density lipoprotein receptor in a dose dependent manner.

Furthermore, Helal et al. ${ }^{[33]}$ conducted a study in animal models in order to demonstrate that the use of caffeine can improve liver damage induced by a high-fat diet (HFD). The rats were divided into 
four groups and treated for 16 weeks as follows: control group; HFD Group; HFD group and $20 \mathrm{mg}$ of caffeine; HFD group and $30 \mathrm{mg}$ of caffeine. HFD-induced liver injury was determined by evaluating the alanine aminotransferase (ALT), aspartate aminotransferase (AST), albumin, bilirubin, triglycerides and cholesterol. Results indicated that caffeine treatment reduced elevated serum levels of ALT, AST, bilirubin and hepatic mRNA expression of fatty acid synthase and acetyl CoA carboxylase.

Chlorogenic acid (CGA) is a phenolic compound that is obtained from the combination of caffeic acid and $(L)$-quinic acid. It belongs to the family of polyphenols, substances with powerful antioxidant actions. It is well known that the polyphenols present in coffee as chlorogenic acid increase the production of antioxidants agents ${ }^{[34]}$. Moreover, caffeine increases peroxiredoxin-1 which has positive effects on ROS, reducing oxidative stress at the level of hepatocytes ${ }^{[34]}$.

The synergistic effect of polyphenols and caffeine on hepatocytes also decreases insulin resistance, while polyphenols contained in caffeine exerts an antifibrotic effect on the liver, an action that has been widely highlighted in studies carried out on obese rats ${ }^{[35]}$. It is present in high concentrations in green coffee and in other typical foods of the Mediterranean diet ${ }^{[36,37]}$. Coffee roasting produces a compound that takes the name of hydroxy-hydroquinone, which however reduces its bioavailability. It is estimated that one liter of coffee provides between 500 and $800 \mathrm{mg}$ of $\mathrm{CGA}^{[38]}$.

Ferulic acid (FA) is a phenolic acid found in coffee, in some cereals such as oats, wheat and rice, in artichokes and in some types of fruit. FA is a derivative of trans-cinnamic acid and is able to interfere with the expression and activity of cytotoxic enzymes such as nitric oxide synthase, caspases and the cyclooxygenase-2. Ferulic acid has been proposed as treatment for neurodegenerative, cardiovascular and diabetic disorders.

Furthermore, it must be emphasized that the interest in this compound has increased due to its potential therapeutic effects to reduce the deposition of triglycerides and cholesterol inhepatocytes, anti-microbial, anti-inflammatory, and anti-tumor properties ${ }^{[39,40]}$.

\section{COFFEE AND NAFLD}

Among the several studies that analyzed the activities of coffee in NAFLD, Hosseinabadi et al. ${ }^{[41]}$ evaluated the effects of green coffee extract (GCE) on the lipid profile and adiponectin levels in patients with NAFLD. The randomized double-blind study was conducted on 48 patients aged between 20 and 60 years with a body mass index (BMI) between $25-35 \mathrm{~kg} / \mathrm{m}^{2}$. In this study the patients were divided into two groups, one group has been treated with $400 \mathrm{mg} / \mathrm{die}$ GCE and the other with placebo. The liver enzymes, lipid profile, adiponectin concentration, and degree of hepatic steatosis were analyzed at the beginning and at the end of the trial. The results showed that GCE supplementation significantly reduced BMI (MD: $-0.57 ; 95 \% \mathrm{CI}$ : -0.84 to $-0.29 ; P<0.001)$. Moreover the study also showed an increase in HDL levels (MD: 7.06; 95\%CI: 0.25 to $13.87 ; P<0.05)$ and a reduction in serum blood triglyceride levels (MD: $-37.91 ; 95 \% \mathrm{CI}:-72.03$ to $-3.80 ; P$ $=0.03)$ and total cholesterol $(\mathrm{MD}:-13.33 ; 95 \% \mathrm{CI}:-26.04$ to $-0.61 ; P<0.05)$ compared to the control group [Table 1].

Graeter et al. ${ }^{[42]}$ have assessed the impact of caffeine consumption on liver fat concentration and ALT values in a total population sample of 1,452 subjects, including 789 women, and 663 men with an average age of 42.3 years. After completing an informative questionnaire on personal data and lifestylewith particular focus on coffee consumption, the liver health of all patients were examined using ultrasound. Univariate logistic regression was used to evaluate the association between caffeine consumption and hepatic steatosis. From the results, a significant association emerged between hepatic steatosis and the male gender $(P<$ $0.0001)$, the same significance was also detected for advanced age subjects $(P<0.0001)$ and the high body- 
Table 1. Studies on coffee in liver diseases

\begin{tabular}{|c|c|c|c|c|c|c|c|}
\hline Author & Year & Design & Population & Disease & Methods & Country & Findings \\
\hline Hosseinabadi et al. ${ }^{[41]}$ & 2020 & $\begin{array}{l}\text { Randomized, } \\
\text { controlled } \\
\text { trial }\end{array}$ & $\begin{array}{l}48(n=24 \\
\mathrm{GCE} 400 \\
\mathrm{mg})(n=24 \\
\text { placebo })\end{array}$ & NAFLD & Ultrasonographic & Iran & $\begin{array}{l}\text { GCE supplementation improved } \\
\text { serum lipid profile and BMI in } \\
\text { individuals with NAFLD. GCE may } \\
\text { be useful in controlling NAFLD risk } \\
\text { factors }\end{array}$ \\
\hline Graeter et al. $^{[42]}$ & 2015 & $\begin{array}{l}\text { Cross- } \\
\text { selectional }\end{array}$ & 1,223 & NAFLD & Ultrasonographic & Germany & $\begin{array}{l}\text { No evidence for an association } \\
\text { between caffeine consumption } \\
\text { and either the prevalence of } \\
\text { hepatic steatosis or serum ALT } \\
\text { concentrations }\end{array}$ \\
\hline Bambha et al. ${ }^{[43]}$ & 2014 & $\begin{array}{l}\text { Cross- } \\
\text { selectional }\end{array}$ & 782 & $\begin{array}{l}\text { NAFLD/ } \\
\text { NASH/ } \\
\text { diabetes }\end{array}$ & $\begin{array}{l}\text { Hepatic } \\
\text { histological data }\end{array}$ & USA & $\begin{array}{l}\text { Coffee intake is associated with } \\
\text { decreased odds of advanced } \\
\text { fibrosis among patients with less } \\
\text { insulin resistance }\end{array}$ \\
\hline Anty et al. ${ }^{[44]}$ & 2012 & Cohort & 195 & $\begin{array}{l}\text { NAFLD/ } \\
\text { NASH/ } \\
\text { obesity }\end{array}$ & Liver biopsies & France & $\begin{array}{l}\text { Consumption of regular coffee but } \\
\text { not espresso is an independent } \\
\text { protective factor for liver fibrosis in } \\
\text { severely obese European patients }\end{array}$ \\
\hline Zelber-Sagi et al. ${ }^{[45]}$ & 2015 & $\begin{array}{l}\text { Cross- } \\
\text { sectional }\end{array}$ & 494 & NAFLD & $\begin{array}{l}\text { Hepato renal } \\
\text { index }(\mathrm{HRI}) \text { and } \\
\text { Steato test }\end{array}$ & Israel & $\begin{array}{l}\text { No association was demonstrated } \\
\text { between coffee consumption and } \\
\text { the new onset of non-alcoholic } \\
\text { fatty liver, but coffee intake may } \\
\text { exert beneficial effects on fibrosis } \\
\text { progression }\end{array}$ \\
\hline Hodge et al. ${ }^{[46]}$ & 2017 & Retrospective & 1,018 & $\begin{array}{l}\text { NAFLD/ } \\
\text { HCV/ } \\
\text { HBV }\end{array}$ & $\begin{array}{l}\text { Transient } \\
\text { elastography } \\
(\mathrm{TE})\end{array}$ & Australia & $\begin{array}{l}\text { Coffee consumption decreases } \\
\text { liver stiffness, which may indicate } \\
\text { less fibrosis and inflammation, } \\
\text { independent of the disease state. } \\
\text { This study adds further evidence } \\
\text { to the notion of coffee, which may } \\
\text { be beneficial in patients with liver } \\
\text { disease }\end{array}$ \\
\hline Alferink et al. ${ }^{[4]]}$ & 2017 & Cohort & 2,424 & NAFLD & $\begin{array}{l}\text { Elastography, } \\
\text { ultrasound }\end{array}$ & Netherlands & $\begin{array}{l}\text { In the general population, frequent } \\
\text { coffee and herbal tea consumption } \\
\text { were inversely related with liver } \\
\text { stiffness but not steatosis }\end{array}$ \\
\hline
\end{tabular}

NAFLD: non-alcoholic fatty liver disease; HCV: hepatitis C virus; HBV: hepatitis B virus; GCE: green coffee extract; ALT: alanine aminotransferase

mass index (BMI; $P<0.0001)$. However, no association was identified between caffeine consumption and liver fat levels, nor between caffeine consumption and high levels of ALT concentrations.

Bambha et al. ${ }^{[43]}$ have analyzed the effects of coffee intake in 782 NAFLD patients ( $n=295$ men) with an average age of $48 \pm 12$ years and an average BMI of $33.5 \mathrm{~kg} / \mathrm{m}^{2}$ with low levels of insulin resistance. Coffee intake was measured by cups per day (cpd), and was represented as follows: $0 \mathrm{cpd}, n=230 ;<1 \mathrm{cpd}, n=219$; $1-<2 \mathrm{cpd}, n=116 ; \geq 2 \mathrm{cpd}, n=217$. During the study, IR was assessed using HOMA-IR and the association between coffee intake and NAFLD histological severity was modeled using multiple logistic regression. The study found that the effect of coffee on fibrosis varied with the degree of insulin resistance (IR) (interaction $P=0.001)$. Coffee consumers with less IR, defined as HOMA-IR $<4.3$, had a lower probability of fibrosis $(\mathrm{OR}=0.64 ; 95 \% \mathrm{CI}: 0.46$ to $0.88 ; P=0.001)$. However, there was no protective effect of coffee on advanced fibrosis among individuals with higher HOMA-IR ( $\mathrm{OR}=1.06 ; 95 \% \mathrm{CI}$ : 0.87 to $1.28 ; P=0.6)$.

In the study of Anty et al ${ }^{[4]]}$ the influence of coffee and other caffeinated drinks on liver fibrosis of severely obese patients was assessed. A total of 195 patients with severe obesity, were enrolled for this trial and were given a specific questionnaire that analyzed the consumption of various types of coffee and other beverages containing caffeine and chocolate. The questionnaires showed that classic coffee and espresso were consumed in $30.8 \%$ and $50.2 \%$ of patients, respectively. According to logistic regression analysis, coffee consumption represents a protective factor for fibrosis [OR: $0.752(0.578-0.9800) ; P=0.035$ ] in a model that 
included the level of AST[(OR: $1.04(1.004-1.076) ; P=0.029]$ and presence of NASH [OR: 2.41 (1.007-5.782); $P=0.048]$.

Zelber-Sagi et $a l .{ }^{[45]}$, evaluated the association between coffee consumption and hepatic steatosis onset in a cohort of 347 patients, comparing them with a control group. Hepatic steatosis was quantified by ultrasound and SteatoTest and the degree of fibrosis was assessed by FibroTest. During recruitment, a questionnaire relating to coffee consumption was filled. The study found that neither the incidence nor the prevalence of steatosis was associated with coffee consumption. Moreover, coffee consumption was associated with a lower clinically significant percentage of fibrosis $\geq \mathrm{F} 2(8.8 \% v$ s. $16.3 \% ; P=0.038)$ and the multivariate logistic regression analysis related the high coffee consumption with a lower probability of fibrosis (probability ratio $=0.49,95 \%$ confidence interval, $0.25-0.97 ; P=0.041$ ). In a retrospective study by Hodge et al ${ }^{[46]}$, a total of 1,018 patients (441 women, 577 men) affected by NAFLD, Hepatitis C (HCV), and hepatitis B (HBV) were recruited for determining the effects of coffee and tea intake on liver stiffness (SE). Data showed that SE was higher in males than in females $(P<0.05)$. HBV patients had a lower SE than those with HCV and NAFLD. Those who drank 2 or more cups of coffee a day had a lower SE $(P=0.044)$. Tea consumption had no effect on SE $(P=0.9)$. The study showed that coffee consumption reduces the SE with a decrease of fibrosis and inflammation.

Alferink et al. ${ }^{[47]}$ recruited 2,424 participants (age $66.5 \pm 7.4 ; 43 \%$ male) who were asked to fill in a questionnaire on eating habits and lifestyle. All patients were examined by liver elastography and ultrasonography to evaluate liver stiffness and the degree of liver steatosis. Coffee and tea consumption were classified into: no intake (0), moderate (>0-3) or frequent intake $\geq 3$ ) (cups/day). Fibrosis was defined as a measure of SE. During course of the study, univariate linear and logistic regression analyzes were performed to examine the association between coffee, herbal /green/black tea consumption and SE. For the regression models, multivariable adjustments were made taking into consideration age, sex, BMI, insulin resistance, steatosis, serum ALT, alcohol intake, smoking, use of cream in coffee, use of sugar in tea or coffee and physical activity. The results showed that the SE was inversely related to a higher consumption of coffee $(7.8 \%, 6.9 \%$ and $4.1 \%$ for non consumption, moderate and frequent respectively; $P$ $=0.006$ ). In general, frequent coffee consumption was inversely related to SE but not to steatosis. More indepth analysis and studies are needed to validate the underlying mechanisms. The daily consumption of three or more cups of coffee was linked to the presence of a low SE, regardless of many other lifestyle and environmental factors.

\section{CONCLUSION}

Although the protective role of coffee in NAFLD is still controversial, several studies have shown that coffee consumption in patients with NAFLD can be protective against liver steatosis, progression of fibrosis and liver damage ${ }^{[48]}$. The antioxidant capacity of coffee has been demonstrated in animal models of fatty liver, in which caffeine intake improves insulin resistance and reduces the production of inflammatory cytokines. Moreover, the weight of the animals and the intrahepatic levels of glucose were reduced with coffee consumption. However, not all the studies were concordant on the protective effect of coffee against NAFLD: controversial results may be due to the heterogeneity of the patients analyzed, the different protocols of research, and the different methods of collecting data. Furthermore, it should be emphasized that the content of caffeine and the different compounds typical of coffee can be influenced by the type of coffee examined, the type of roasting, the volume of water used, and the type of grinding: all these elements should therefore be standardized to avoid variations in the concentration of the most active compounds.

In conclusion, the overall trend emerging from the literature review suggests that regular coffee consumption might be a protective factor against the evolution of NAFLD complications, especially liver fibrosis. Additional studies should be carried out to further characterize the correlation between coffee and 
NAFLD. Many studies are still controversial by designs, methods, amount of caffeine or type of coffee used, measurements, different population investigated but research in this area should also focus on assessing the potential in taking this drink, quantifying the methods and number of intakes that generate an effective advantage. Pending further research, we can suggest that moderate consumption of 2-3 cups of coffee a day in patients with NAFLD should be encouraged.

\section{DECLARATIONS}

\section{Authors' contributions}

Wrote, reviewed and edited the manuscript: Calabrò A, Procopio AC, Gualtieri P

Provided the tables: Calabrò A, Procopio AC, Gualtieri P

Reviewed and approved the final manuscript as submitted: Primerano F, Larussa T, Luzza F

Read and approved the final manuscript: Di Renzo L, De Lorenzo A, Abenavoli L

Conceptualized and designed the review: Abenavoli L

\section{Availability of data and materials}

Not applicable.

\section{Financial support and sponsorship}

None.

\section{Conflicts of interest}

All authors declared that there are no conflicts of interest.

\section{Ethical approval and consent to participate}

Not applicable.

\section{Consent for publication}

Not applicable.

\section{Copyright}

(c) The Authors(s) 2020.

\section{REFERENCES}

1. Asrani SK, Devarbhavi H, Eaton J, Kamath PS. Burden of liver diseases in the world. J Hepatol 2019;70:151-71.

2. Abenavoli L, Procopio AC, Medić-Stojanoska M, Luzza F. Non-alcoholic fatty liver disease and primary care physicians. Minerva Gastroenterol Dietol 2020;66:4-5.

3. Abenavoli L, Milanović M, Milić N, Luzza F, Giuffrè AM. Olive oil antioxidants and non-alcoholic fatty liver disease. Expert Rev Gastroenterol Hepatol 2019;13:739-49.

4. Rinella M, Charlton M. The globalization of nonalcoholic fatty liver disease: Prevalence and impact on world health. Hepatology 2016;64:19-22.

5. Abenavoli L, Peta V, Milic N. Lifestyle changes associated with a new antioxidant formulation in non-alcoholic fatty liver disease: a case series. Ann Hepatol 2015;14:121-6.

6. Michel M, Schattenberg JM. Effectiveness of lifestyle interventions in NAFLD (nonalcoholic fatty liver disease) - how are clinical trials affected? Expert Opin Investig Drugs 2020;29:93-7.

7. Lonardo A, Mantovani A, Lugari S, Targher G. NAFLD in some common endocrine diseases: prevalence, pathophysiology, and principles of diagnosis and management. Int J Mol Sci 2019;20:2841.

8. Gelli C, Tarocchi M, Abenavoli L, Di Renzo L, Galli A, et al. Effect of a counseling-supported treatment with the Mediterranean diet and physical activity on the severity of the non-alcoholic fatty liver disease. World J Gastroenterol 2017;23:3150-62.

9. Abenavoli L, Milanovic M, Procopio AC, Spampinato G, Maruca G, et al. Ancient wheats: beneficial effects on insulin resistance. Minerva Med $2020 \mathrm{Jul} 28$; [Online ahead of print].

10. Brunner KT, Henneberg CJ, Wilechansky RM, Long MT. Nonalcoholic Fatty Liver Disease and Obesity Treatment. Curr Obes Rep 2019;8:220-8. 
11. Hamurcu Varol P, Kaya E, Alphan E, Yilmaz Y. Role of intensive dietary and lifestyle interventions in the treatment of lean nonalcoholic fatty liver disease patients. Eur J Gastroenterol Hepatol 2020;32:1352-7.

12. Cai J, Zhang XJ, Li H. Progress and challenges in the prevention and control of nonalcoholic fatty liver disease. Med Res Rev 2019;39:328-48.

13. Abenavoli L, Di Renzo L, Boccuto L, Alwardat N, Gratteri S, et al. Health benefits of Mediterranean diet in nonalcoholic fatty liver disease. Expert Rev Gastroenterol Hepatol 2018;12:873-81.

14. Abenavoli L, Boccuto L, Federico A, Dallio M, Loguercio C, et al. Diet and non-alcoholic fatty liver disease: the mediterranean way. Int J Environ Res Public Health 2019;16:3011.

15. Abenavoli L, Milic N, Luzza F, Boccuto L, De Lorenzo A. Polyphenols Treatment in Patients with Nonalcoholic Fatty Liver Disease. J Transl Int Med 2017;5:144-7.

16. Abenavoli L, Milic N, Di Renzo L, Preveden T, Medić-Stojanoska M, et al. Metabolic aspects of adult patients with nonalcoholic fatty liver disease. World J Gastroenterol 2016;22:7006-16.

17. Di Renzo L, Cioccoloni G, Bernardini S, Abenavoli L, Aiello V, et al. A hazelnut-enriched diet modulates oxidative stress and inflammation gene expression without weight gain. Oxid Med Cell Longev 2019;2019:4683723.

18. Araújo AR, Rosso N, Bedogni G, Tiribelli C, Bellentani S. Global epidemiology of non-alcoholic fatty liver disease/non-alcoholic steatohepatitis: what we need in the future. Liver Int 2018;38 Suppl 1:47-51.

19. Luk JM, Wang X, Liu P, Wong KF, Chan KL, et al. Traditional Chinese herbal medicines for treatment of liver fibrosis and cancer: from laboratory discovery to clinical evaluation. Liver Int 2007;27:879-90.

20. Philips CA, Augustine P, Rajesh S, Y PK, Madhu D. Complementary and alternative medicine-related drug-induced liver injury in Asia. J Clin Transl Hepatol 2019;7:263-74.

21. Richmond JA, Bailey DE, Patel K, Jezsik JA, Muir A, et al. The use of complementary and alternative medicine by patients with chronic hepatitis C. Complement Ther Clin Pract 2010;16:124-31.

22. Henson JB, Brown CL, Chow SC, Muir AJ. Complementary and alternative medicine use in United States adults with liver disease. J Clin Gastroenterol 2017;51:564-70.

23. Nieber K. The impact of coffee on health. Planta Med 2017;83:1256-63.

24. Costa J, Lunet N, Santos C, Santos J, Vaz-Carneiro A. Caffeine exposure and the risk of Parkinson's disease: a systematic review and meta-analysis of observational studies. J Alzheimers Dis 2010;20 Suppl 1:S221-38.

25. Crippa A, Discacciati A, Larsson SC, Wolk A, Orsini N. Coffee consumption and mortality from all causes, cardiovascular disease, and cancer: a dose-response meta-analysis. Am J Epidemiol 2014;180:763-75.

26. Nordestgaard AT, Stender S, Nordestgaard BG, Tybjaerg-Hansen A. Coffee intake protects against symptomatic gallstone disease in the general population: a Mendelian randomization study. J Intern Med 2020;287:42-53.

27. Lopez-Garcia E, van Dam RM, Li TY, Rodriguez-Artalejo F, Hu FB. The relationship of coffee consumption with mortality. Ann Intern Med 2008;148:904-14.

28. Freedman ND, Park Y, Abnet CC, Hollenbeck AR, Sinha R. Association of coffee drinking with total and cause-specific mortality. N Engl J Med 2012;366:1891-904.

29. Nehlig A, Daval J, Debry G. Caffeine and the central nervous system: mechanisms of action, biochemical, metabolic and psychostimulant effects. Brain Res Rev 1992;17:139-70.

30. Shim SG, Jun DW, Kim EK, Saeed WK, Lee KN, et al. Caffeine attenuates liver fibrosis via defective adhesion of hepatic stellate cells in cirrhotic model. J Gastroenterol Hepatol 2013;28:1877-84.

31. Gressner OA, Lahme B, Rehbein K, Siluschek M, Weiskirchen R, et al. Pharmacological application of caffeine inhibits TGF-betastimulated connective tissue growth factor expression in hepatocytes via PPARgamma and SMAD2/3-dependent pathways. J Hepatol 2008;49:758-67.

32. Quan HY, Kim DY, Chung SH. Caffeine attenuates lipid accumulation via activation of AMP-activated protein kinase signaling pathway in HepG2 cells. BMB Rep 2013;46:207-12.

33. Helal MG, Ayoub SE, Elkashefand WF, Ibrahim TM. Caffeine affects HFD-induced hepatic steatosis by multifactorial intervention. Hum Exp Toxicol 2018;37:983-90.

34. Perumpail BJ, Li AA, Iqbal U, Sallam S, Shah ND, et al. Potential therapeutic benefits of Herbs and supplements in patients with NAFLD. Diseases 2018;6:80.

35. Watanabe S, Takahashi T, Ogawa H, Uehara H, Tsunematsu T, et al. Daily coffee intake inhibits pancreatic beta cell damage and nonalcoholic steatohepatitis in a mouse model of spontaneous metabolic syndrome, tsumura-suzuki obese diabetic mice. Metab Syndr Relat Disord 2017;15:170-7.

36. Di Renzo L, Marsella LT, Carraro A, Valente R, Gualtieri P, et al. Changes in LDL oxidative status and oxidative and inflammatory gene expression after red wine intake in healthy people: a randomized trial. Mediators Inflamm 2015;2015:317348.

37. Colica C, Di Renzo L, Trombetta D, Smeriglio A, Bernardini S, et al. Antioxidant effects of a hydroxytyrosol-based pharmaceutical formulation on body composition, metabolic state, and gene expression: a randomized double-blinded, placebo-controlled crossover trial. Oxid Med Cell Longev 2017;2017:2473495.

38. Meng S, Cao J, Feng Q, Peng J, Hu Y. Roles of chlorogenic acid on regulating glucose and lipids metabolism: a review. Evid Based Complement Alternat Med 2013;2013:801457.

39. Zduńska K, Dana A, Kolodziejczak A, Rotsztejn H. Antioxidant properties of ferulic acid and its possible application. Skin Pharmacol Physiol 2018;31:332-6. 
40. Sarwar T, Zafaryab M, Husain MA, Ishqi HM, Rehman SU, et al. Redox cycling of endogenous copper by ferulic acid leads to cellular DNA breakage and consequent cell death: A putative cancer chemotherapy mechanism. Toxicol Appl Pharmacol 2015;289:251-61.

41. Hosseinabadi S, Rafraf M, Asghari S, Asghari-Jafarabadi M, Vojouhi S. Effect of green coffee extract supplementation on serum adiponectin concentration and lipid profile in patients with non-alcoholic fatty liver disease: a randomized, controlled trial. Complement Ther Med 2020;49:102290.

42. Graeter T, Niedermayer PC, Mason RA, Oeztuerk S, Haenle MM, et al; EMIL-Study group. Coffee consumption and NAFLD: a community based study on 1223 subjects. BMC Res Notes 2015;8:640.

43. Bambha K, Wilson LA, Unalp A, Loomba R, Neuschwander-Tetri BA, et al; Nonalcoholic Steatohepatitis Clinical Research Network (NASH CRN). Coffee consumption in NAFLD patients with lower insulin resistance is associated with lower risk of severe fibrosis. Liver Int 2014;34:1250-8.

44. Anty R, Marjoux S, Iannelli A, Patouraux S, Schneck AS, et al. Regular coffee but not espresso drinking is protective against fibrosis in a cohort mainly composed of morbidly obese European women with NAFLD undergoing bariatric surgery. J Hepatol 2012;57:1090-6.

45. Zelber-Sagi S, Salomone F, Webb M, Lotan R, Yeshua H, et al. Coffee consumption and nonalcoholic fatty liver onset: a prospective study in the general population. Transl Res 2015;165:428-36.

46. Hodge A, Lim S, Goh E, Wong O, Marsh P, et al. Coffee intake is associated with a lower liver stiffness in patients with non-alcoholic fatty liver disease, Hepatitis C, and Hepatitis B. Nutrients 2017;9:56.

47. Alferink LJM, Fittipaldi J, Kiefte-de Jong JC, Taimr P, Hansen BE, et al. Coffee and herbal tea consumption is associated with lower liver stiffness in the general population: the Rotterdam study. J Hepatol 2017;67:339-48.

48. Furtado KS, Prado MG, Aguiar E, Silva MA, Dias MC, et al. Coffee and caffeine protect against liver injury induced by thioacetamide in male Wistar rats. Basic Clin Pharmacol Toxicol 2012;111:339-47. 